\title{
Sanal Kaytarma: Ankara'da Bulunan A Grubu Seyahat Acenteleri Üzerine Bir Araştırma (Cyberloafing: A Research on Group A Travel Agencies in Ankara)
}

\author{
Mahmut EFENDi (iD a Funda ODUNCUOĞLU (iD $b$ \\ a Aydın Adnan Menderes Üniversitesi, Turizm Fakültesi, Aydın, Türkiye. efendimahmut926@gmail.com \\ b Aydın Adnan Menderes Üniversitesi, Söke İşletme Fakültesi, Aydın, Türkiye. funda.cengiz@adu.edu.tr
}

\section{MAKALE BİLGÍsí \\ Anahtar Kelimeler: \\ Seyahat acenteleri Sanal kaytarma İşgören \\ Gönderilme Tarihi 18 Eylül 2020 Revizyon Tarihi 27 \\ Ocak 2021 \\ Kabul Tarihi 10 Mart 2021}

Makale Kategorisi: Araştırma Makalesi

\section{ÖZET}

Amaç - Çalışma Ankara'da bulunan A grubu seyahat acentelerinde çalışan personelin sosyal medya araçlar vasıtasıyla sanal kaytarma davranışı sergileyip sergilemedikleri ortaya koymak amacı ile yapılmaktadır. Bu amaçtan hareketle seyahat acentesi yöneticilerinin konuya ilişkin görüşlerine başvurulmuş ve çalıştırdıkları personelin sanal kaytarma davranışlarına ilişkin düşünceleri öğrenilmeye çalışılmıştır.

Yöntem - Nitel araştırma desenine göre tamamlanan çalışma kapsamında seyahat acenteleri yöneticilerine açık uçlu soru formu ile sorular sorulmuştur. Bu bağlamda 12 seyahat acentesi yöneticisi ile 10/09/2019 ve 25/12/2019 arasında görüşmeler tamamlanmıştır. Konuyla ilgili yüz yüze görüşme tekniğinin seçilmesinin nedeni, seyahat acentesi yönetici veya sahiplerinin fikirlerinin daha yüzyüze görüşmelerde daha anlaşılır olarak düşünülmesidir.

Bulgular - Araştırmada, seyahat acentelerinde çalışanların genel olarak, Facebook, Instagram, Watsapp, Yahoo, Youtube gibi sosyal medya araçlarını ve şahsi maillerini kullandıkları anlaşılmaktadır. İlgili acentelerde çalışan tüm personelin sosyal medya araçlarını iş zamanında kullandığı görülmektedir. Personelin sosyal medyada harcadığı süreye ilişkin ise genel görüş 0-2 saat aralığında yoğunlaşmaktadır. Bu tür uygulamaların iş vakti dışında kullanılmasını normal karşıladıklarını ve bunun personelin motivasyonunu artırıcı rol oynadı̆̆ını ifade etmişlerdir. Özellikle işletmeye ait sosyal medya hesaplarının olmasının bu konuda daha esnek davranmalarına neden olduğunu göstermektedir. Bunun yanında bazı yöneticiler ise sanal kaytarma yapılmasını uygun görmediklerinin, kullananları ikaz ettiklerini belirtmişlerdir.

Tartışma - Araştırma sonuçlarına göre seyahat acentesi personelinin iş zamanlarında sanal kaytarma davranışı sergiledikleri ve bunların sosyal medya araçlarından Instagram, Facebook, Youtube, Yahoo ve şahsi mail adreslerini kullanarak yaptıkları anlaşılmaktadır. Yöneticilerin çalışanlara işyerinde sanal kaytarma yapmamaları ya da bunun kontrollü biçimde yapmaları gerektiğine ilişkin telkinlerde bulunmaları gerekliliği öne çıkmaktadır.

\section{ARTICLE INFO \\ Keywords: \\ Travel agencies \\ Cyberloafing \\ Employee}

Received 18

September 2020

Revised 27 January

2021

Accepted 10 March 2021

Article Classification: Research Article

\section{ABSTRACT}

Purpose - The study was carried out in order to reveal whether the employees working in Group A travel agencies in Ankara exhibited cyberloafing behaviors through social media tools. For this purpose, the views of the travel agency managers regarding the subject were obtained and their views regarding the cyberloafing behaviors of their employees were asked.

Design/methodology/approach - Within the scope of this study, which was completed according to qualitative research design, questions were asked to the travel agency managers through an open-ended questionnaire form. In this regard, the interviews were completed with 12 travel agency managers between 10/09/2019 and $25 / 12 / 2019$. The reason for preferring face-to-face interview technique was that the views of the travel agency managers or owners were obtained in a more understandable manner during face-to-face interviews.

Findings - In the research, it was understood that the employees working in the travel agencies generally usedsuch applications as Facebook, Instagram, WhatsApp and Yahoo. It was revealed that all the employees working in the related agencies used social media tools during working hours. The general opinion regarding the time spent by the employees on social media was between 0-2 hours. They stated that the use of such applications out of workinghourswas regarded as normal and this played a significant role in increasing the motivation of the employees. It was also expressed that they were especially more flexible as the enterprises had their own social media accounts. In addition to this, some managersemphasized that they did not find cyberloafing acceptableand therefore, they warned the employees when they saw them using during working hours.

Discussion - According to the results of the research, it was understood that the employees working in the travel agencies exhibited cyberloafing behaviors during working hours and that they performed these behaviors by using such social media tools as Instagram, Facebook, YouTube and personal e-mail addresses. It is recommended that the managers are required to advise their employees not to perform cyberloafing behaviors in the workplace or perform so in a controlled manner.

\section{Önerilen Atıf/ Suggested Citation}

Efendi, M., Oduncuoğlu, F. (2021). Sanal Kaytarma: Ankara'da Bulunan A Grubu Seyahat Acenteleri Üzerine Bir Araștırma, İşletme Araştırmaları Dergisi, 13 (1), 304-316. 


\section{Giriş}

Örgütsel motivasyonları, örgütsel bağlılıkları ve iş tatminleri yüksek personelin işletmelerin rekabet edebilme gücünde önemli etkileri vardır. Sürdürülebilir rekabet avantajı elde edebilmek için ise bilginin ve bilgiye ulaşmanın en önemli araçlarından biri olan teknolojinin etkin kullanımı işletmeler açısından en az personel kadar önemli sayılmaktadır. Teknolojinin ve özelinde internetin iş yaşamını kolaylaştırıp personelin iş performansını yükseltmede bir takım avantajlar sağlamasının yanında personelin ve işletmelerin üzerinde olumsuz etkileri de bulunmaktadır (Ulukapı ve Yılmaz, 2014: 65, Çavuşoğlu ve Palamutçuoğlu, 2017: 431). İnternet maliyeti azaltma, üretim döngüsü sürelerini kısaltma, bilgi erişimini kolaylaştırma ve pazarlama hizmetleri ve ürünlerin daha etkin olması gibi birçok fayda getirse de olumsuz etkileri de tartışılmıştır. Bu olumsuzluklardan biri de sanal kaytarmadır. Teknolojinin hızla gelişimi ile birlikte çalışanlarında internet kullanımı artmakta olduğu söylenebilir. Teknoloji iş akışını kolaylaştırma ve kalitesini artırma konusunda önemli avantajlar sağlasa da iş yerindeki internet kullanımının karanlık yüzünü de göz ardı etmemek gerekmektedir. Çalışanlar işleri ile ilgili görevlerini yerine getirmek için interneti ve bilgisayarı kullanabildiği gibi çalışma saatleri içerisinde bu teknolojiyi işle ilgili olmayan eylemler için de kullanabilmektedir (Baturay ve Toker, 2015: 358, Ayazlar, Sayman ve Çınar, 2018: 25). Sanal kaytarma, çalışanların, mesai saatleri içerisinde, bilgisayar, cep telefonu, tablet gibi teknoloji ürünleri aracıllğıyla internet erişimlerini işle ilgisi olmayan konularda yani kişisel amaçlar için kullanmalarıdır (Vitak and Larose, 2011: 1753). Personelin iş saatlerini sanal kaytarma ile geçirmesinin yöneticilerce kabul edilemez olması varsayımı neticesinde bilgi yoğunluklu çalışanlar sanal kaytarmayı gizlemek için daha gelişmiş ve karmaşık yöntemler ararlar (Aghazand Sheikh, 2016: 52). Çalışan tarafında iş yerinde sıkılma iş deneyiminin diğer önemli bir yönüdür vesanal kaytarma, çalışanın bu sıkıntıyla baş etme tepkisi olarak da değerlendirilmektedir. (Pindek, Krajcevska and Spector, 2018: 147).

Yabancı yazında sık olarak kullanılan bir kavram olan sanal kaytarma, yerli yazında yeni bir çalışma alanı olma özelliğine sahiptir. Sanal kaytarma ile ilgili Türkiye'de sınırlı sayıda çalışma bulunmakla birlikte, gerek yerli, gerekse yabancıyazında konunun farklı sektörler açısından ele alınması gerektiğine sıklıkla vurgu yapılmaktadır (Blanchard and Henle, 2008; Kaplan ve Ögüut, 2012; Örücü ve Yıldız, 2014, Genç ve Aydoğan, 2015). Bu bağlamda, sanal kaytarma sektörel olarak değerlendirildiğinde, gerek emek yoğun yapısı gerekse teknoloji kullanımının giderek artması nedeniyle Turizm sektörünün de sanal kaytarma açısından incelenmesi gerekmektedir. Müşteri memnuniyeti odaklı bu sektörde çalışanlar; Uzun çalışma saatleri, sürekli güler yüzlü hizmet sunumu, bitmeyen müşteri talepler ve sürekli değişen beklentiler neticesinde diğer sektörlerden daha farklı ve yoğun bir çaba içinde hizmet sunmaktadırlar ve bu çalışma koşulları çalışanlar üzerinde baskı oluşturmaktadır (Turunç, 2015: 146). Bu baskı da personeli sanal kaytarmaya yönlendirebilmektedir.

Turizm sektöründe teknoloji kullanımının en yoğun olduğu işletmeler ise seyahat acenteleridir. Seyahat acentelerinin faaliyetlerini gerçekleştirebilmeleri için teknolojik altyapıya yatırım yapmaları, pazardaki gelişmeleri takip etmeleri, rakipleri, yeni ürün ve hizmetleri analiz etmeleri, müşterilerin istek ve ihtiyaçlarını tamamlamaları ve gerekli ekipmanı bünyelerine almaları gerekmektedir (Seçilmiş ve Yılmaz, 2018). Rekabetin çok yoğun olduğu turizm sektöründe, yeni gelişmeleri takip edemeyen ve kendini geliştiremeyen seyahat acenteleri yok olmaya mahkûmdur. Bu noktada seyahat acentelerinin sahip olduğu en önemli kaynaklar teknoloji ve insan faktörü olarak ön plana çıkmaktadır. Bu bağlamda bu çalışmada internetin yoğun biçimde kullanıldı $\breve{g}$ seyahat acentelerinde çalışan personelin sanal kaytarma davranışlarının incelenmesi amaçlanmıştır. Bu amaçtan hareketle seyahat acentesi yöneticilerinin konuya ilişkin görüşlerine başvurulmuş ve çalıştırdıkları personelin sanal kaytarma davranışlarına ilişkin düşünceleri öğrenilmeye çalışılmıştır.

\section{Kavramsal Çerçeve}

Sanal kaytarma, "çalışanların ofis saatleri sırasında kişisel amaçları için işle ilgili olmayan konularda şirketin internet erişimini kullanan gönüllü eylemi" olarak tanımlanmaktadır (Lim, 2002: 690 ; Aghaz and Sheikh, 2016: 52).Bir başka tanıma göre sanal kaytarma, çalışanın iş görevlerini gerçekleştirmek yerine kişisel veya rekreasyon olarak elektronik cihazları kullanmasıdır (Lim and Teo, 2005: 1083). Geniş bir bakış açısıyla; çalışanların mesai zamanında iş dışı internet kullanımı, siber sapkınlık, işte kişisel internet kullanımı, internet suiistimali, işyerinde eğlence amaçlı gezinme ve gereksiz bilgisayar kullanımı olarak tanımlanan (Vitak and Larose, 2011: 1751 ; Lim, 2002: 675, Örücü ve Özüdoğru, 2019: 68) sanal kaytarma davranış1, örgütlerde maliyet kayıplarına ve güvenlik sorunlarına neden olabilmektedir.Her ne kadar şirketler yazılım ve verilerine yetkisiz 
erişimi engellemek için antivirüs ve güvenlik duvarı yazılımlarına yatırım yapsalar da en yıkıcı ve pahalı bilgisayar suçları, şirketin bilgisayar sistemine yasal erişimi olan bireyler tarafından işlenmektedir (Laudon and Laudon, 2002: 124). Bu aktiviteleri engellemek için şirketler çalışan izleme/gözleme yazılımları kullanmaktadır. (Zimmerman, 2002: 41).

Konuya ilişkin yapılan araştırmalar incelendiğinde ağırlıklı olarak sanal kaytarma tipik bir zarar verici çekilme davranışı olarak kabul edilmekte ve örgüt liderleri de sürekli olarak çalışanların bu davranışlarda bulunmasını önlemeye çalışmaktadır (Ugrin and Pearson, 2013: 816).

Ancak araştırmacılar bu varsayımı sorgulamaya başlamıştır. Örneğin son zamanlarda gerçekleştirilen bir meta analizin kanıtları, yaygın varsayımların aksine sanal kaytarmanın çalışanların iş performansını olumsuz olarak etkilemediğini göstermiştir (Mercado, Giordano and Dilchert, 2017: 551). Diğer araştırmacılar ise daha da ileriye giderek sanal kaytarmanın çalışanların ruh halini iyileştirme (Lim and Chen, 2012: 687) ve çalışanların işe katılımını arttırmak (Syrek, Kühnel, Vahle-Hinzand De Bloom, 2018: 214) gibi olumlu etkileri olduğunu bulmuşlardır. Yakın zamanlı bir araştırmada araştırmacılar aynı zamanda çalışanların stresli iş koşullarına tepki olarak sanal kaytarmada bulunduğunu (Henle and Blanchard, 2008: 389; Pindek vd., 2018: 148) göstererek sanal kaytarmanın çalışanların iş stresiyle baş etme mekanizması olabileceğine dair ilk kanıtları sunmuştur.

Van Doorn (2011: 127) sanal kaytarmanın nedenlerini üç kategori altında incelemiştir. Bunlar;

- Örgütsel Nedenler: Örgüt tarafından uygulanan internet politikası, çalışanların sanal kaytarma davranışlarını etkilemektedir. Bunun dışında örgütün çalışanlarına zaman ve yer açısından kısıtlama getirmemesi de sanal kaytarma davranışlarını etkilemektedir.

- İşle İlgili Nedenler: İş talebinin az ya da çok olması, çalışanların sanal kaytarma davranışlarını artıırırken, denge durumunda ise sanal kaytarma davranışları azalmaktadır (Blanchard ve Henle, 2008: 393).

- Kişilik Özellikleri: Landers and Lounsbury (2006) yaptıkları araştırmalarında, çalışanların kişilik özelliklerinin, sanal kaytarma davranışlarını etkilediğini tespit etmişlerdir.

Alanyazın incelendiğinde, sanal kaytarma etkinliklerinin de araştırmacılar tarafından farklı sınıflandırmalara tabi tutulduğu görülmektedir. Blanchard and Henle (2008: 1068) sanal kaytarma tiplerini önemsiz (kısa süreli haber sitelerini ziyaret etme, e-posta alma, okuma, gönderme gibi) ve ciddi (kumar içerikli sitelere girme, sohbet etme/chat yapma gibi) sanal kaytarma olarak iki şekilde tasnif etmiştir. Bu sınıflandırma bu araştırmada baz alınan sınıflandırma şeklidir. Ramayah (2010) ise sanal kaytarma faaliyetlerini, kişisel iletişim, kişisel bilgi araştırması, kişisel veri indirme ve kişisel çevrimiçi alışveriş yapma olarak 4 kategoriye ayırmıştır. Ayrıca, Li and Chung (2006: 1069) sanal kaytarmayı dört farklı kategoriye göre ayırmaktadırlar; Sosyal fonksiyon (İnterneti kullanarak arkadaşlarla iletişim kurmak), bilgi edinme fonksiyonu (İnterneti kullanarak bilgi sahibi olmak) , eğlence fonksiyonu (eğlence için interneti kullanmak) ve sanal duygusal fonksiyon (bahis veya randevulaşma gibi diğer faaliyetler için interneti kullanmak).

Dünyada giderek önem kazanan sanal kaytarma davranışı yurt dışında olduğu kadar ülkemizde de akademik alanda öne çıan, güncel bir araştırma konusu haline gelmiştir. Konuya ilişkin ülkemizde gerçekleştirilen araştırmalar incelendiğinde turizm sektöründe de farklı açılardan konunun ele alındığı görülmektedir. Bu araştırmalara ilişkin önemli örneklerden biri Serttaş'ın (2016) Turizm işletmelerinde sanal kaytarma davranışını incelediği araştırmadır. Araştırmacı Kuşadası'nda faaliyet gösteren 4 ve 5 yıldızlı konaklama işletmelerinde önbüro bölümlerindeki işgörenlerden toplanan veri ile mesai saatleri içerisinde sanal kaytarma davranışında bulunup bulunmadığını tespit etmeyi amaçlamıştır. Araştırma sonucunda işgörenlerin orta düzeyde sanal kaytarma davranışı sergiledikleri ve bu davranışların işle ilgisi olmayan web sitelerini ziyaret etme biçiminde yoğunlaştığı sonucuna ulaşılmıştır (Serttaş ve Şimşek, 2017). Konuya ilişkin yapılan diğer bir çalışma Demir ve Tan'ın (2018) otel işletmelerinde işgörenlerin işle ilgisi olmayan ve sanal kaytarma davranışları ile demografik özellikleri arasındaki ilişkinin olup olmadığını belirlemeyi amaçladıkları araştırmadır. Araştırma sonucunda iş görenlerin bazı demografik özellikleri ile sanal kaytarma davranışı arasında anlamlı ilişkinin olduğu belirlemişlerdir (Demir ve Tan, 2018). Konuya ilişkin turizm sektöründe yapılan diğer bir çalışma ise Yıldırım'ın (2018) yıldırma ve işe yabancılaşmanın sanal kaytarma davranışına etkisinin ölçülmesi ve bu etkide psikolojik sözleşme ihlali algısının aracı rol oynayıp oynamadığının ortaya konması amacıyla gerçekleştirdiği araştırmadır. Yıldırım, otel işletmelerinin müşterilerine sundukları hizmet 
gereği, çalışanlar için sanal kaytarmaya uygun ortamlar barındırdığını ve sanal kaytarma davranışının sadece denetim sistemleri veya kontrol mekanizmaları ile engellemenin mümkün olmadığını, bu nedenle işgörenleri sanal kaytarma davranışına iten örgütsel nedenlerin ortaya konması gerektiğini savunmuştur (Yıldırım, 2018). Direk olarak seyahat acentelerinde sanal kaytarma davranışını konu alan bir çalışma ise Seçilmiş ve Yılmaz'ın (2018) seyahat acentesi çalışanlarının sanal kaytarma davranışları ile iş motivosyanları arasındaki ilişkiyi inceledikleri araştırmadır. Eskişehir'de faaliyet gösteren seyahat acentelerinde çalışan 196 acente çalışanı ile anket aracılığı ile veri toplanmıştır. İş motivasyonunun alt boyutları olarak "yönetim biçimi", "maaş ve teşvikler", "iş yeri güvenliği", "takım çalışması" ve "kişisel gelişim"in alındığı araştırma sonucunda "maaş ve teşvikler" ile "kişisel gelişim" boyutları ile sanal kaytarma davranışı arasında anlamlı ve pozitif yönlü ilişkinin olduğu tespit edilmiştir (Seçilmiş ve Yılmaz, 2018).

Genel olarak alanyazın değerlendirildiğinde seyahat acentelerinin iş ortamında daha fazla internete bağlanma gereksinimi daha fazla sanal kaytarmaya neden olabilmektedir denilebilir (Ayazlar, vd., 2018: 33). Öncelikle turizm ve özelinde seyahat acentelerinde internet kullanımının yoğunlaşması ve hizmet kalitesinin önemi neticesinde de sanal kaytarma davranışının işletmelere olumsuz sonuçlar doğurabileceği söylenebilir. Bu bağlamda seyahat acentelerinde çalışan personelin sanal kaytarma davranışlarının incelenmesi ve buna ilişkin önlemlerin alınarak doğru yönlendirmelerin yapılabilmesi önem arz etmektedir.

\section{Yöntem}

$\mathrm{Bu}$ çalışma seyahat acentelerinin yöneticilerinin bakış açısıyla işletmelerinde çalışan personelin sanal kaytarma davranışında bulunup bulunmadıklarının ortaya koyulması amacıyla yapılmaktadır. Ayrıca eğer yapıyor ise, sanal kaytarma yapan personelin, seyahat acentesi sahipleri veya yöneticilerinin işletmede sahip olduğu işgücünü ne kadar azalttığının ortaya konulma ek amacı bulunmaktadır.

Nitel araştırmalarda örneklem belirlenirken temsil gücünden çok örneğin araştırma konusu ile olan ilgisi dikkate alınır (İslamoğlu, 2009: 183). Bu çalı̧̧mada da olasılıklı olmayan örnekleme türlerinden kartopu örnekleme seçilmiştir. Bu örnekleme yöntemi araştırmacıya hız ve pratiklik kazandırır. Çünkü bu yöntemde araştırmacı yakın olan ve erişilmesi kolay olan bir durumu seçer (Yıldırım ve Şimşek, 2006: 113).

İlk olarak Ankara'da bir seyahat acentası sahibinden telefon ile randevu alınmış ve kendisiyle görüşmeye gidilmiştir. Bu bağlamda 10/08/2019 tarihinde görüşülen acente sahibinden kendisinden sonra diğer seyahat acentelerinin sahipleri ve yöneticileri ile görüşmek için telefonlar isteneceği belirtilmiştir. Buna bağlı olarak seçilen yöntem aşağıda vurgulanmıştır.

Araştırmanın evrenini Ankara' da bulunan seyahat acenteleri oluşturmaktadır. Bu bağlamda nitel veri toplama yöntemi olarak seçilen görüşme, yarı yapılandırılmış biçimde hazırlanmıştır. Açı uçlu soruların yer aldığı yarı-yapılandırılmış görüşme formu hazırlanarak, işletme sahipleri veya yöneticileri ile yüz yüze görüşmeler gerçekleştirilmiştir. Arıca (2014), “Seyahat İşletmeciliği Literatürünün Gelişim Süreci: Türkiye'de Hazırlanan Lisansüstü Tez Çalışmalarının Bibliyometrik Olarak İncelenmesi" konulu çalışmasında, turizm alanında seyahat acentelerine yönelik nitel çalışmaların genel itibariyle örneklem sayısının 0-50 arasında olduğunu ifade etmiştir. Bu bağlamda 12 seyahat acentesi yöneticisi ile 10/09/2019 ve 25/12/2019 arasında görüşmeler tamamlanmıştır. Görüşmeler 30-45 dk arasında sürmüş ve ses kayıt cihazı katılımcıların istememesinden dolayı kullanılmamıştır. Araştırmacının zincirleme bir şekilde sürdürdüğü araştırma sonucunda veri doygunluğuna ulaşıldığı anda araştırmanın veri toplama aşaması tamamlanır (Kerlinger and Lee, 1999). Bu bağlamda araştırma içerisinde katılımcıların verdikleri yanıtların tekrarlanması durumunda veya benzer yanıtlar verilmesine bağlı olarak yeterli sayıya ulaşıldığı düşünülmüştür.

Görüşme yapılanlardan 8 tanesi seyahat acentesi sahibi iken 4 tanesi seyahat acentesi yöneticisidir. Çalışma için yapılan görüşmelerde seyahat acenteleri seçilirken kartopu örneklem yöntemi seçilmiştir.Görüşme sürecinde geçerlik ve güvenirlik sağlanması açısından aynı sorular, aynı sözcüklerle yöneltilmiştir. Çalışma içerisinde yapılan görüşmelerde gözlem yapılması sonucunda olumlu izlenimlerin elde edilmesi, katılımcıların istekli olması ve görüşme sonrası iki araştırmacı tarafından verilerin incelenmesi geçerlik ve güvenirlik sağlayan diğer etkenlerdir (Baran, 2019: 7). Ayrıca araştırmanın geçerliliğini sağlamak için katılımcı teyidi sağlanmıştır. Katılımcı teyidi (katılımcı kontrolü) veriden ve çalışılan kişilerden gelen sonuçların sistematik olarak dönüt alınmasıdır (Çevikbaş, 2018: 126). Yapılan görüşmelerden elde edilen verilerin özgün şekline mümkün olduğunca bağlı kalınarak ve gerektiğinde katılımcıların ifadelerinden doğrudan alıntı 
yapılarak betimsel bir yaklaşımla sunulmuştur (Karataş, 2015: 72).Araştırmada veri toplama yöntemi olarak görüşme tekniği yönteminin kullanılmasının sebebi elde edilmek istenilen verilerin ölçekli sorularla elde edilmesinin mümkün olmaması ve araştırmaya konu olan işletme sayısının az olmasıdır (Ayyıldız-Yazıcı, Esen ve Ayyıldız, 2019: 414). Yarı yapılandırılmış görüşmenin anketten farkı, görüşme deneklerin, bireyin veya grupların dünya hakkındaki görüşlerini göstermektedir. Daha basit bir ifade ile açıllanır ise görüşmede yorum ve gözlemler de toplanabilmektedir. (Clark, Riley, Wilkie and Wood, 2000). Konuyla ilgili yüz yüze görüşme tekniğinin seçilmesinin nedeni, seyahat acentesi yönetici veya sahiplerinin fikirlerinin daha yüzyüze görüşmelerde daha anlaşılır olarak düşünülmesidir.

Çalışmada elde edilen verilerin analizi, söylem veya içerik analizi yoluyla incelenmiştir. Bu çalışma içerisinde nitel araştırma yöntemlerinde veri analizinden söylem analizi ile tamamlanmıştır. Söylem analizi bireylerin doğada ortaya çıkan belirli olaylar ya da davranışlar hakkında kendi kişisel gerçeklerini nasıl oluşturdukları üzerine yoğunlaşmaktadır ve karşılıklı konuşma özelliğinin yansıtması nedeniyle, bir bakıma her nitel veri analizi, kısmen de olsa, bir söylem analizini yansıtmaktadır (Kozak, 2018: 127). Araştırma içerisinde sorulan sorular araştırmacılar tarafından literatürden yararlanılarak hazırlanmıştır. Literatürde daha önce yapılmış olan çalışmalardan Örücü ve Yıldız (2014), Settaş ve Şimsek (2017), Kaplan ve Çetinkaya (2014) tarafından yapılan çalışmalardan derlenerek hazırlanmıştır. Hazırlanan sorular alanında uzman üç akademisyene gösterilmiş ve onaylatılmıştır. Bu bağlamda seyahat acentesi yöneticilerine aşağıdaki sorular sorulmuştur

1- Demografik sorular

2- Hizmet verdiğiniz seyahat acentesinde personeliniz hangi sosyal medya araçlarını kullanıyor?

3- Hizmet verdiğiniz seyahat acentesinde çalışan personeliniz iş zamanlarında sosyal medyada zaman harcıyor mu? (ek soru: hangilerinde ve günlük ortalama ne kadar zaman harcıyor?)

4- Hizmet verdiğiniz seyahat acentesinde personelinizin iş zamanlarında sosyal medya araçlarını kullanmaması konusunda uyarılarda bulunuyor musunuz? (ek soru: uyarı için neler söylüyorsunuz? Bu konuda cezalar veriyor musunuz?)

5- Hizmet verdiğiniz seyahat acentelerinde çalışan personeliniz sizce neden sanal kaytarma yapıyorlar? (Açıklar mısınız?)

\section{Bulgular}

Tablo 1. Yöneticilerin Demografik Bilgileri

\begin{tabular}{|l|l|}
\hline 1- Cinsiyet & Erkek: 10 \\
& Kadın: 2 \\
\hline 2-Yaş & $30-39: 5$ \\
& $40-49: 3$ \\
& $50-59: 3$ \\
& 60 ve üzeri: 1 \\
\hline 3-Eğitim & Lise: 5 \\
& Ön lisans: 2 \\
& Lisans: 4 \\
& Yüksek Lisans: 1 \\
\hline 4-Sektör deneyimi & $10-19$ yıl: 6 \\
& $20-29$ yıl: 5 \\
& $30-39$ yıl: 1 \\
\hline 5-Medeni Durum & Evli: 8 \\
& Bekar: 4 \\
\hline 6-İsletmedeki görev & Sahibi veya ortağ1: 6 \\
& Yönetici:6 \\
\hline
\end{tabular}


7- Personel sayıs1

$$
\begin{aligned}
& \text { 1-4: } 6 \\
& \text { 5-8: } 4 \\
& \text { 9-12: } 1 \\
& \text { 23 ve üstü:1 }
\end{aligned}
$$

Araştırmaya katılan katılımcıların demografik özelliklerine ilişkin tablo 1 incelendiğinde katılımcıların 10'u $(\%$ 83,3) erkek ve 2'si $(\%$ 16,6) kadındır. Katılımcılara ilişkin yaş dağılımın bakıldığında 30-39 yaş aralığında 5 (\% 41,6), 40-49 yaş aralığında 3 (\% 25) 50-59 yaş aralığında 3 (\% 25) ve 60 yaş ve üzeri yaş aralığında ise 1 (\% $8,3)$ katılımcı olduğu görülmektedir. Katılımcıların eğitim seviyelerine ilişkin bulgular incelendiğinde lise mezunu 5 (\% 41,6), ön lisans mezunu 2 (\% 16,6), lisans mezunu 4 (\% 33,3) ve yüksek lisans mezunu 1 (\% 8,3) katılımcı olduğu görülmektedir. Katılımcıların 6'sının (\% 50) sektör deneyimi 10-19 yıl aralığında, 5'nin (\% 41,6) 20-29 yıl aralığında ve 1'inin 30-39 yıl aralığındadır. Katılımcılardan 8'i (\% 66,6) evli, 4'ü (\% 33,3)ise bekar olduğunu belirtmiştir. Katılımcılardan 6’sı (\%50) işletmenin sahibi ya da ortağ1 konumunda görev yaparken 6'sı ise (\% 50) yönetici konumunda görev yaptıklarını belirtmişlerdir. Demografik sorulardan sonuncusu olan işletmelerinde çalışan personel sayısına ilişkin olarak katılımcılardan 6’sı (\% 50) işletmelerinde 1-4 aralığında çalışan olduğunu, 4’ü (\% 33,3) 5-8 arasında çalışan olduğunu, 1'i (\% 8,3) 9-12 arasında çalışan olduğunu ve 1'i de $(8,3) 23$ ve üzeri çalışan olduğunu belirtmiştir.

Tablo 2. Çalışanların Sosyal Medya Kullanımı

\begin{tabular}{|l|l|l|l|l|l|l|}
\hline Soru2- Hizmet verdiğiniz seyahat acentesinde personeliniz hangi sosyal medya araçların kullanıor? \\
\hline Katılımc1 & Facebook & İnstagram & Twitter & Watsapp & Yahoo & Youtube \\
\hline Katılımc1 1 & X & X & & X & & X \\
\hline Katılımc1 2 & X & X & X & X & & X \\
\hline Katılımc1 3 & X & X & X & X & X & \\
\hline Katılımc1 4 & X & X & X & X & X & X \\
\hline Katılımc1 5 & X & X & X & X & X & X \\
\hline Kat1lımc1 6 & X & X & & X & X & X \\
\hline Katılımc1 7 & X & & & & & X \\
\hline Katılımc1 8 & X & X & & & & \\
\hline Kat1lımc1 9 & X & X & & X & & X \\
\hline Kat1lımc1 10 & X & X & & & & \\
\hline Katılımc1 11 & X & X & & & & \\
\hline Kat1lımc1 12 & & X & X & & & \\
\hline
\end{tabular}

Katılımcıların hizmet verdikleri seyahat acentelerinde personellerinin hangi sosyal medya araçlarını kullandığına ilişkin soruya verdikleri yanıtların gösterildiği tablo 2 incelendiğinde Facebook uygulamasının 12 acenteden 11'inde (\% 91,6) personel tarafından kullanıldığı yine benzer biçimde Instagram uygulamasının da 12 acenteden 11'inde (\% 91,6) personel tarafından kullanıldığı belirtilmiştir. Bu en çok kullanılan iki uygulamanın ardından sirasiyla Whatsapp'ın 7 acentede (\% 58,3), Youtube'un 7 acentada (\%58,3), Twitter'ın 5 acentede (\% 41,6), Yahoo'nun 4 acentede (\% 33,3) çalışan personel tarafından kullanıldı̆̆ görülmektedir.

\section{Tablo 3. İş zamanlarında Sosyal Medya Kullanımı}

\begin{tabular}{|l|l|}
\hline $\begin{array}{l}\text { Soru 3: Hizmet verdiğiniz seyahat acentesinde çalışan personeliniz iş zamanlarında sosyal medyada } \\
\text { zaman harcıyor mu? (ek soru: hangilerinde ve günlük ortalama ne kadar zaman harcıyor?) }\end{array}$ \\
\hline Katılımcı & Sosyal Medya Kullanım Süresi \\
\hline Katılımcı 1 & $\begin{array}{l}\text { Evet, tüm personelimiz sosyal medyada zaman harcıyor. Gözlemlerime göre bu süre } \\
\text { 0-2 saat arasındadır. Bunun yanında iş için kullandıkları zamanlarda buna dahil. }\end{array}$ \\
\hline Katılımcı 2 & $\begin{array}{l}\text { Tüm personelimizin sosyal medya araçları bulunuyor ve bunları aktif olarak iş } \\
\text { sürelerinde de kullanıyorlar. Ortalama olarak 0-2 saat arasında kullanımları vardır. }\end{array}$ \\
\hline Katılımcı 3 & $\begin{array}{l}\text { Kesinlikle sosyal medya araçlarını kullanıyorlar. Bu bakımdan ortalama olarak } \\
\text { günlük 3-5 saat aralığındadır. }\end{array}$ \\
\hline
\end{tabular}




\begin{tabular}{|c|c|}
\hline Katılımcı 4 & $\begin{array}{l}\text { Facebook, Twitter ve Watsapp ağırlıklı olarak kullanıyorlar. 0-2 saat aralığındadır } \\
\text { diye düşünüyorum. }\end{array}$ \\
\hline Katılımcı 5 & Ortalama olarak günde 0-2 saatleri sosyal medya ile geçiriyorlardır. \\
\hline Katılımcı 6 & Bütün personelimiz sosyal medya kullanıyor. 3-5 saat arasında kullanımları vardır. \\
\hline Katilimcı 7 & Hepsi sosyal medya kullanıyor ve ortalama süreleri 0-2 saat arasındadır. \\
\hline Katılımc1 8 & $\begin{array}{l}\text { Boş zaman buldukça sosyal medyalarına giriş yapıyorlar. Tahmini olarak 0-2 saat } \\
\text { kullanımları olduğunu düşünüyorum. }\end{array}$ \\
\hline Katılımc1 9 & $\begin{array}{l}\text { Harcamaya çalışıyorlar. Şirket hesabı hariç şahsi hesapları ile ilgili kullandıklarını } \\
\text { gördüğümde uyarıyorum. Yinede azda olsa kullanıyorlardır. Günlük 0-2 saat } \\
\text { aralığında kullanıyorlardır. }\end{array}$ \\
\hline Katılımc1 10 & $\begin{array}{l}\text { Tümünün sosyal medya kullandığını görüyorum. Ortalama olarak 3-5 saat } \\
\text { arasındadır. }\end{array}$ \\
\hline Katılımcı 11 & $\begin{array}{l}\text { İş süresince şahsi hesaplarıyla telefonlarıyla ve bilgisayar aracılığı ile sosyal medya } \\
\text { araçlarını kullanıyorlar. Günlük ortalama 0-2 saat arası kullanım yapıyorlardır. }\end{array}$ \\
\hline Katılımcı 12 & $\begin{array}{l}\text { İş saatleri içerisinde 0-2 saat arasında sosyal medya araçlarını kullandıklarını } \\
\text { düşünüyorum. }\end{array}$ \\
\hline
\end{tabular}

Araştırmanın üçüncü sorusunda katılımcılara acentelerinde çalışan personelin iş zamanlarında sosyal medyada zaman harcayıp harcamadığı sorulmuş ve eğer harcıyorlarsa bu sürenin ne kadar olduğuna ilişkin ek bilgi vermeleri istenmiştir. Bu soruya ilişkin katılımcıların verdiği yanıtlar tablo 3'de görülmektedir. Genel olarak katılımcıların verdiği yanıtlar değerlendirildiğinde, ilgili acentelerde çalışan tüm personelin sosyal medya araçlarını iş zamanında kullandığı görülmektedir. Personelin sosyal medyada harcadığı süreye ilişkin ise genel görüş 0-2 saat aralığında yoğunlaşmaktadır.

\section{Tablo 4. Kullanım İle İlgili Uyarılar}

Soru 4: Hizmet verdiğiniz seyahat acentesinde personelinizin iş zamanlarında sosyal medya araçlarını kullanmaması konusunda uyarılarda bulunuyor musunuz? (ek soru: uyarı için neler söylüyorsunuz? Bu konuda cezalar veriyor musunuz?)

\begin{tabular}{|l|l|}
\hline Katılımcı & Kullanım İle İlgili Uyarılar \\
\hline Katılımcı 1 & $\begin{array}{l}\text { Sosyal medya kullanımı konusunda uyarılarda bulunmuyorum. İ̧ saatlerinde } \\
\text { personelin yoğun olduğu zamanlar dışında kullanmasında bence sorun yok hatta } \\
\text { motivasyon aracı oluyor. Bazen çok aşırıya kaçıyorlar, aslında buda tam olarak iş } \\
\text { yapması gereken zamanda iş ile ilgilenmek yerine sosyal medya ile ilgilenir ise } \\
\text { uyarılarda bulunuyorum. Ceza verme gibi bir durum yoktur eğer birkaç saatin } \\
\text { üstünde sürekli bunu yapar ise işten çıkarmaya gidebileceğimi biliyorlar. }\end{array}$ \\
\hline Katılımcı 2 & $\begin{array}{l}\text { Bazen çalışan personelimi uyarmak zorunda kalıyorum. Bunun nedeni iş saatinde iş } \\
\text { yapması gerekliliği. Tabiki bizim ile ilgili sosyal medya araçlarını kullandıklarında } \\
\text { hiçbir şey demiyoruz çünkü firmamıza ait sosyal medya hesapları da bulunmaktadır. } \\
\text { Bu konuda herhangi bir ceza veya yaptırım uygulamıyorum. }\end{array}$ \\
\hline Katılımcı 3 & $\begin{array}{l}\text { Bizim personelimiz yüksek derecede sosyal medya kullanıyor ve bunu iş ile ilgili } \\
\text { olarak kullanıyorlar. Bazı durumlarda şahsi hesaplarına giriş yapıyorlar bunu da } \\
\text { normal olarak görüyorum. }\end{array}$ \\
\hline
\end{tabular}




\begin{tabular}{|c|c|}
\hline Katılımcı 4 & $\begin{array}{l}\text { Kesinlikle uyarılarda bulunmuyorum. Sonuçta iş saatleri içerisinde tüm zamanlarını } \\
\text { harcamaları beklenemez. Onlarında molalara dinlenmelere ihtiyaçları var. }\end{array}$ \\
\hline Katılımcı 5 & $\begin{array}{l}\text { İşletmemizde uyarılarda bulunmak zorunda kalıyorum. Kullandıkları süre çok fazla } \\
\text { olmasa dahi yinede bazen gerekli oluyor. Kendilerini kaptırıyorlar. }\end{array}$ \\
\hline Katılımcı 6 & $\begin{array}{l}\text { Firmamızda çalışan personele uyarılarda bulunuyoruz. Aşırı derecede kullanımının } \\
\text { olduğu zamanlar oluyor. Buda işlerini etkiliyor. Aslında iş zamanında iş mola } \\
\text { zamanında keyif olması gerekiyor. }\end{array}$ \\
\hline Katılımc1 7 & $\begin{array}{l}\text { Firmamızda çalışanlar az dahi olsa sosyal medya kullanımı yapıyorlar. Bu konuda } \\
\text { çok uyarma gereği duymuyorum. Aslında gözlerimden anlıyorlar demek daha doğru } \\
\text { olur. }\end{array}$ \\
\hline Katılımcı 8 & $\begin{array}{l}\text { İşi zamanında kullanmamaları konusunda uyarılarda bulunuyorum. Buna tüm } \\
\text { çalışma saatlerinde ihtiyaç duyuyoruz. Personelimin kullanımı konuştuğum diğer } \\
\text { firmalardaki arkadaşlarıma göre daha az olsa dahi kullanıyorlar. Ceza uygulamasam } \\
\text { dahi yaptıkları hatalardan kaynaklanan para kayıplarını kendilerinden tahsil } \\
\text { edeceğimi söylüyorum. }\end{array}$ \\
\hline Katılımc1 9 & $\begin{array}{l}\text { Sosyal medya kısıtlaması yapmıyoruz. Bunun nedeni şirketimize bağlı sosyal medya } \\
\text { hesaplarının da bulunması. Tabiki firmamıza ait hesapların takip ve beğenme oranını } \\
\text { arttırma koşuluyla. }\end{array}$ \\
\hline Katılimcı 10 & $\begin{array}{l}\text { Sosyal medya kullanımı yapıyorlar uyarılarda yapıyoruz. Bunun yanında } \\
\text { hayatımızın vazgeçilmezi şuan için elimizden geldiğince engellemeye çalışıyoruz. }\end{array}$ \\
\hline Katılimcı 11 & $\begin{array}{l}\text { İş zamanında ne kadar fazla kullanamayın desek dahi büyük bir iş zamanını orada } \\
\text { harcıyorlar. Hatta bunun yüzünden birkaç kişiyi işten çıkarmışlığımız var. }\end{array}$ \\
\hline Katılimcı 12 & $\begin{array}{l}\text { Günümüzde tüm herkesin sosyal medya kullandığını düşünüyorum bu yüzden bir } \\
\text { şey demem. Firmamızda da sosyal medya araçlarını reklam ve tanıtım amaçlı } \\
\text { kullanıyoruz. }\end{array}$ \\
\hline
\end{tabular}

Araştırmanın kilit sorularından biri olan dördüncü soruda katılımcılara personellerinin sosyal medya kullanımları konusunda bir uyarıda bulunup bulunmadıkları ve şayet uyarıyorlarsa bu konuda nasıl bir yol izlediklerine ilişkin görüşleri öğrenilmeye çalışılmıştır. Tablo 4'de katılımcıların ilgili soruya verdikleri yanıtlar incelendiğinde görüş ayrılıkları yaşandığını söylemek mümkündür. Konuya ilişkin olarak 6 katılımcı sosyal medya kullanımının günümüzün bir gereği olduğunu ve bunun yadsınamayacağını belirtmiştir. Bu tür uygulamaların iş vakti dışında kullanılmasını normal karşıladıklarını ve bunun personelin motivasyonunu artırıcı rol oynadığını ifade etmişlerdir. Özellikle işletmeye ait sosyal medya hesaplarının olmasının bu konuda daha esnek davranmalarına neden olduğunu göstermektedir. Bu katılımcılar aynı zamanda iş saati içinde ve aşırıya kaçıldığı takdirde ikazda bulunulabileceğini belirtmişlerdir. Diğer 6 katılımcı ise konuya ilişkin daha sert bir tutum sergilemektedirler. Personelin iş saati içinde sosyal medya kullanmalarını doğru bulmadıklarını, bu tür uygulamalarda geçirilen vaktin performanslarını olumsuz yönde etkilediğini, engellenmediği ya da uyarılmadığı takdirde aşırıya kaçılabildiğini belirtmişlerdir. Bu katılımcılardan bazıları sosyal medya uygulamalarında geçirilen vaktin doğru ayarlanamaması durumunda işten çıkarılmaya kadar giden cezai yaptırımların uygulanabildiğini ve muhakkak bu konuda personellerini uyardıklarını belirtmişlerdir. 
Tablo 5. Personelin Sosyal Medya Kullanım Gereksinimi

\begin{tabular}{|c|c|}
\hline Katilimc1 & Sanal Kaytarma Nedenleri \\
\hline Katılımc1 1 & $\begin{array}{l}\text { Temelinde teknoloji ile beraber alışkanlıkların değiştiğini düşünüyorum. Haber } \\
\text { verme haber alma ve bir bakıma sosyalleşme olarak düşünüyorum. }\end{array}$ \\
\hline Katılımc1 2 & $\begin{array}{l}\text { Tamamen bağımlılık olarak görüyorum. Herkes günde en az birkaç saat telefonuna } \\
\text { bakıyor. Hatta boş ekranlara bile bakıyorlar arayan oldu mu olmadı mı diye. } \\
\text { Personelim şahsi hesapları için kısa süreli sosyal medya kullanımında bulunuyor. }\end{array}$ \\
\hline Katılımc1 3 & $\begin{array}{l}\text { Şahsi hesaplarına gelen mesajlarını okumak, cevaplamak ve karşılık vermek } \\
\text { amacıyla kullanıyorlar. Bağımlılı diye düşünsem dahi işimizde dahi } \\
\text { kullanmalarını istiyorum çağa ayak uydurmak olarak görüyorum. }\end{array}$ \\
\hline Katılımc1 4 & $\begin{array}{l}\text { Gereksinim olarak düşünüyorum. Bu nedenle hiç laf etmem. Kendimde } \\
\text { kullanıyorum. }\end{array}$ \\
\hline Katılımc1 5 & Sosyal medya kullanımını alışkanlık, merak ve takip isteği olarak görüyorum. \\
\hline Katılimci 6 & İş yoğunluğunun az olması bence sanal kaytarma yapması için bir durum yaratıyor. \\
\hline Katılımc1 7 & $\begin{array}{l}\text { Sanal kaytarma yapma nedenleri tamamen alışkanlık. Telefon bağımlılık haline } \\
\text { geldi diye düşünüyorum. }\end{array}$ \\
\hline Katılımc1 8 & $\begin{array}{l}\text { Şahsi telefonlarına gelen mesajlardan dolayı sanal kaytarma yapıyorlar. Bu } \\
\text { bakımdan alışkanlık diyorum. Ayrıca az dahi olsa bağımlılık diyorum. Sürekli aynı } \\
\text { işi yapmaktan kaynaklanan sıkılma olarak görüyorum. }\end{array}$ \\
\hline Katılımc1 9 & $\begin{array}{l}\text { Sosyal medya kullanımının bağımlılık olduğunu düşünüyorum. Sürekli olarak } \\
\text { telefona bakma isteği ayrıca boş zaman değerlendirme aktivitesi olarak da } \\
\text { düşünülebilir. }\end{array}$ \\
\hline Katılımc1 10 & $\begin{array}{l}\text { Merak diyorum öncelikle sonra ise, işten sıkılma ve kişisel amaçlı olarak } \\
\text { görüyorum. }\end{array}$ \\
\hline Katılımc1 11 & Bağımlılık olduğunu düşünüyorum ve bu nedenden işten kaytarıyorlar. \\
\hline Katılımc1 12 & Zaman geçirme, eğlence ve yoğunluktan kaçma olarak görüyorum. \\
\hline
\end{tabular}

Araştırmanın son sorusu olan 5. Soruda katılımcılara hizmet verdikleri seyahat acentelerinde çalışan personellerininneden sanal kaytarma yaptıklarını açıklamaları istenmiştir. Bu soruya ilişkin katılımcıların verdiği yanıtlarda dikkat çeken iki önemli unsur; katılımcıların neredeyse tamamının sosyal medya kullanımını alışkanlık ve bağımlılık olarak nitelendirmesidir. Sosyal medyanın günlük hayatın içinde vazgeçilmez bir unsur olduğunu ve bu durumun kendileri içinde geçerli olduğunu düşünen katılımcılar, her ne kadar kullanıma ilişkin sıklığın özellikle cep telefonlarına olan bağımlılıktan kaynaklandığını düşündüklerini belirtseler de aynı zamanda bunu bir sanal kaytarma olarak da değerlendirmekte olduğunu belirtmişlerdir. Ayrıca bunun özellikle zaman geçirme, eğlenme ve yoğunluktan kaçma olarak nitelendirmektedirler. Katılımcılardan ikisi ise konuya farklı bir açıdan bakarak personellerinin sosyal medyayı iş saatlerinde aktif biçimde kullanmalarının sanal kaytarma olmadığını düşündüklerini belirtmişler bunun bir gereksinim ve ötesi çağa ayak uydurmak için zorunluluk olarak gördüklerini ifade etmişlerdir. 


\section{Sonuç ve Tartışma}

Araştırmanın sonuçları genel olarak değerlendirildiğinde seyahat acentesi personelinin sanal kaytarma davranışında bulundukları söylenebilir. Bu olası ve alanyazın da desteklenen bir sonuç olmakla birlikte acente yöneticilerinin bu davranışa ilişkin bakış açılarında farklılıklar gözlenmiştir. Alanyazında günde yaklaşık 2 ile 3 saat aralığında gerçekleştirildiği öne sürülen sanal kaytarma davranışının (Zakrzewski, 2016), seyahat acentesi personeli tarafından da benzer sürelerde gerçekleştirildiği yöneticilerden alınan yanıtlarla desteklenmiştir. Birkaç katılımcı sanal kaytarmanın 3-5 saat aralığında olduklarını belirtmişlerdir. Bu bağlamda katılımcılar verdikleri ek bilgilerde çalışan personelin teknoloji çağında işyerinde sürekli olarak internet kullanma gereklilikleri olduğunu ve işlerini düzgün yaptıkları zamanlarda bir saat veya fazlasında sanal kaytarma yapmalarının önemli olmadığını düşünmektedirler.

Seyahat acentesi personelinin iş zamanlarında sosyal medya araçlarını kullanmaması konusunda yöneticilerin personele yönelik takındığı tutum da alanyazın ile benzer biçimde ikiye ayrılmaktadır. İnternet kullanımının ve sosyal medyanın takip edilmesinin örgüte sağlayacağı olası yararlar bulunmaktadır. İnternet kullanımının çalışanların bilgiye ulaşarak, örgütün verimliliğine katkı sağlamasının yanında (Seymour and Nadesan, 2007: 544, Kaplan ve Çetinkaya, 2014: 26),sanal kaytarmanın çalışanların iş performansını olumsuz olarak etkilemediğini (Mercado, vd., 2017)ve ötesinde sanal kaytarmanın çalışanların ruh halini iyileştirme (Lim and Chen, 2012) ve çalışanların işe katılımını arttırma (Syrek, vd., 2018) gibi olumlu etkileri olduğunu savunan çalışmalara benzer biçimde acente yöneticilerinden bazıları çalışanlarının sanal kaytarma davranışını negatif karşılamadıklarını aksine bunun iş motivasyonlarını arttırıcı yönde etki ettiğini düşündüklerini ifade etmişlerdir. Bu bağlamda seyahat acentesi sahipleri ve yöneticilerinin araştırma içerisinde belirttikleri üzere işletmenin çalışma saatleri içerisinde "her saat sessizce oturmak yerine motivasyonu çalı̧̧anlarımıza biz sağlamalıyız" bu isteklendirme ister çay kahve saati ile olsun isterse sanal kaytarma ile fark etmez uygulanmalıdır. Bunun yanında katılımcıların bir kısmı ise sanal kaytarma davranışının örgütlerde maliyet kayıplarına ve güvenlik sorunlarına neden olabildiğini belirtmişlerdir. Bu bağlamda internetten alınabilecek bilgilerin yanında bilgi kayıplarına da yol açabileceğine dikkat çekilmektedir. Ayrıca, olumsuz ve engellenmesi gereken bir davranış olduğunu (Laudon and Laudon, 2002; Zimmerman, 2002; Örücü ve Yıldız, 2014: 101; Çavuşoğlu ve Palamutçuoğlu, 2017: 440 ) savunan araştırmaları destekler biçimde sanal kaytarma davranışının farkında olduklarını ve bunu engellemek için uyarılarda bulunarak bir takım cezalar uygulayabildiklerini belirmişlerdir. Özler ve Polat (2012: 11-12) Çalışanların sanal kaytarma bağlamında hatalı davranışlarını kontrol edebilme noktasında yazında iki temel strateji önermektedir: İçsel yönlü oto kontrol ve dışsal yönlü zorlayıcı stratejiler. Oto kontrol yaklaşımı, bir bireyin içinden gelerek kurallara uymasına odaklanırken; zorlayıcı stratejilerde çalışanların davranışları çevrelerindeki dışsal koşullar tarafından yönlendirilir. Zorlayıcı stratejiler, çalışanların bir kararın fayda ve maliyetlerini karşılaştırarak rasyonel bir şekilde davranmaları ile ilişkilidir (Kaplan ve Çetinkaya, 2014: 33). Sanal kaytarmadan caydırma konusunda ise katılımcılardan bazıları oto kontrol yöntemini benimserken bir kısmının ise zorlayıcı stratejileri benimsediği söylenebilir.

Sanal kaytarmanın, çalışanları psikolojik olarak iş yeri stres faktörünün olumsuz etkilerinden uzaklaştırdığını öne süren çalışmalar vardır. Bu hipotezi ampirik kanıtlarla desteklenmektedir: belirsiz veya çatışmalı iş beklentileri gibi iş stres faktörü deneyimleyen çalışanlar kaçma ve duyguya odaklanan baş etme formu olarak sanal kaytarmada bulunmaktadır (Henle and Blanchard, 2008). Benzer sonuçlar, Pindek vd. (2018) tarafından da bulunmuş ve çalışanların stresli iş deneyimleriyle baş etmek için sanal kaytarmada bulunduğu gösterilmiştir. Bu aynı zamanda literatürde yer alan "mikro ara" veya iş günü sırasında kısa süreli resmi olmayan aralarla uyumludur (Fritz vd., 2011). Örneğin Zacher vd., (2014) tarafından gerçekleştirilen bir günlük çalışması, kısa süreli molaların çalışanların gün içinde kaybettiği enerjiyi kazanmasına izin vererek iş talepleri ve stresle duygusal olarak baş etmek için gerekli kaynakları sunduğunu göstermiştir. Bu araştırmaları destekler nitelikte katılımcıların pek çoğu sanal kaytarmayı iş yükü ile baş etme,stresi azaltma ve işe motive olma konusunda gerçekleştirilebilir bir davranış olarak görmektedir.

Alanyazında çoğu sanal kaytarmayı tamamen zarar verici iş yeri davranışı olarak kavramsallaştırsa da mevcut çalışmanın sonuçları sanal kaytarmanın aynı zamanda iş yerinde kalmanın olumsuz etkilerini azaltabilecek duygu odaklı baş etme mekanizması da olabileceğini öne sürmektedir. Bu sonuçlar sanal kaytarmanın iş yerinde daha önce ele alınandan daha karmaşık bir çıkarımı olduğunu iddia etmektedir. Bunun nedeni bir 
yandan sanal kaytarmanın çalışanların önemli iş görevlerin çekilmesiyle üretkenlik kaybı sayesinde örgüte zarar verebilecek olmasıdır. Diğer yandan sanal kaytarma mikro ara olarak davranarak çalışanların iş yerindeki stres etkenleriyle baş etmesine izin veren kısa ve gönüllü aralar olarak görev yaparak artan memnuniyet ve azalan iş değiştirme niyetleri şeklinde çalışanlar için olumlu çıkarımlar sunabilir (Zacher vd., 2014). Bu bağlamda çalışma içerisinde katılımcılardan toplanan bilgiler benzerlik göstermektedir. Çünkü yöneticilerin büyük bir kısmı sanal kaytarmanın artık engellenemeyeceğini, normal olduğunu ve çalışanların işlerini yaptıkları sürece sıkıntı yaratmayacağını düşündüklerini belirterek teknoloji çağında bir çok şeyin değişebileceğini belirtmişlerdir. Artık evden çalışma ortamının bile yaratıldığı günümüzde çalışanlara baskı kurmak yerine motive ederek daha başarılı sonuçlar alınacağı düşünülmektedir. Gerçeğinde çalışanları saat ile sınırlamak yerine verimli çalışmalarını motive etmek için esnek iş saatleri bile sunulabileceği düşünülmektedir. Sanal kaytarma kavramının yok olmasa dahi kötü bir davranış olarak gösterilmesi yerine motive edici bir davranış olarak bile görülmesi gelecekte yapılacak çalışmalar için etkili olacaktır.

\section{Öneriler}

Çalışma zaman ve maliyet kısıtları nedenleri ile sınırlı sayıda A grubu seyahat acentesi yöneticisiyle gerçekleştirilmiştir. Bunun yanında gelecekte yapılacak araştırmaların daha fazla yönetici ile yapılması araştırmaların geliştirilmesi için verimli olacaktır. Ayrıca araştırmanın gerek seyahat acentesi çalışanları üzerine gerekse turizm sektörünün farklı iş kollarında gerçekleştirilmesi de emek yoğun bir sektör olan turizm sektöründe sanal kaytarmanın mevcut durumunun ortaya çıkarılması ve konuya ilişkin net öngörülerde bulunulabilmesi açısından önerilebilir. Araştırma sonuçlarında özellikle sanal kaytarmanın doğru yönetilmesi halinde işletmeye ve personele olumlu etkile yaratabileceği bulgusundan hareketle yöneticilerin çalışanlara işyerinde sanal kaytarma yapmamaları ya da bunun kontrollü biçimde yapmaları gerektiğine ilişkin telkinlerde bulunmaları gerekliliği öne çıkmaktadır. İş zamanında yapılması gerekenlerin hatırlatılması gerek personele gerekse yöneticilere pozitif biçimde dönecektir. Son olarak araştırma bölgesel olarak tanımlanmış ve uygulanmıştır ve belirli demografik değişikliklerin eşlik ettiği sadece bir alanda uygulanmıştır. Görevler arası ve farklı sektörlerde gerçekleştirilmesiyle daha faydalı sonuçlar bulunabileceği öngörülebilir.

\section{Kaynakça}

Aghaz, A. and Sheikh, H. (2016). Cyberloafing and job burnout: An investigation in the knowledge intensive sector. Computers in Human Behavior, 62, 51-60.

Arıca, R. (2014). “Seyahat işletmeciliği literatürünün gelişim süreci: Türkiye“de hazırlanan lisansüstü tez çalışmalarının bibliyometrik olarak incelenmesi", VII. Lisansüstü Turizm Öğrencileri Araştırma Kongresi, Kuşadası, Aydın, 04-05 Nisan 2014, 446-462.

Ayazlar-Arslan, R., SaymanE. ve Çınar, M. (2018). Turizm öğrencilerinin stajda sanal kaytarma eylemleri. Adnan Menderes Üniversitesi, Sosyal Bilimler Enstitüsü Dergisi, 5 (3), 24-37.

Altınay, M, Güçer, E. ve Bağ, C. (2017). Consumer behavior in the process of purchasing tourism product in social media. İşletme Araştırmaları Dergisi. 9(1), 381-402.

Ayyıldız-Yazıcı, A., Esen, Ö. ve Ayyıldız, T. (2019). Kırsal turizm bölgelerinde festivallerin destinasyon imajına etkisi: Kuşadası Caferli Örneği, Türk Turizm Araştırmaları Dergisi, 3(4),1409-1420.

Baran-Güçlütürk, G. (2019). Unutulmaz gezi deneyimleri: turist rehberlerinden yansımalar. Journal of Travel andTourism Research 14 (2019), 01-20.

Baturay, M. H. ve Toker, S. (2015). An investigation of the impact of demographics on cyberloafing from an educational setting angle, Computers in Human Behavior, 50, 358-366.

Blanchard, A. L.,andHenle, C. A., (2008).Correlates of differentforms of cyberloafing: The role of norms and externallocus of control, Computers in Human Behavior, 24(3), 1067- 1084

Clark, M. A.,Riley, M. J., Wilkie, E. and Wood, R. (2000). Researching and writing dissertations in hospitality and tourism, London: International Thomson Bussiness Press.

Çavuşoğlu, S.ve Palamutçuoğlu, T.- B. (2017). İş tatmininin sanal kaytarma üzerindeki etkisi. Mehmet Akif Ersoy Üniversitesi Sosyal Bilimler Enstitüsü Dergisi, 9 (19): 430-444. 
Çevikbaş, S. (2018). Geçerlik, ne derece hata yapabilirsiniz. Çevikbaş, M. Nitel Araştırma Tasarımı. Nobel Akademik Yayınc1lı. Ankara. 121-139.

Demir, M. ve Tan, M.(2018). Relationship between demographic characteristic of employees and cyberloafing behavior. Journal of Tourism Theory and Research, 4(1), 40-56.

Genç, E. ve Aydoğan, E. (2015), “İşyerinde sanal tembellik davranışı ve etkin zaman yönetimi ilişkisi: Bir kamu kurumunda araştırma”, 23. Ulusal Yönetim ve Organizasyon Kongresi kitabı.

Fritz, C., Lam, C. F., and Spreitzer, G. M. (2011). It's the little things that matter: An examination of knowledge workers' energy management. Academy of Management Perspectives, 25(3), 28-39.

Henle, C. A.,andBlanchard, A. L. (2008). The interaction of work stres ors and organizationals anctions on cyberloafing. Journal of Managerial Issues, 383-400.

Karataş, Z. (2015). Sosyal bilimlerde nitel araştırma yöntemleri. Manevi Temelli Sosyal Hizmet Araştırmaları Dergisi, 1(1), 62-80.

Kaplan, M. ve Öğüt, A. (2012). “Algılanan örgütsel adalet ile sanal kaytarma arasındaki ilişkinin analizi: Hastane çalışanları örneği”, Dokuz Eylül Üniversitesi 20. Yönetim ve Organizasyon Kongresi Bildiriler Kitab1, 592- 596.

Kaplan, M. ve Çetinkaya, Ş.-A. (2014). Sanal kaytarma ve demografik özellikler açısından farklılıklar: Otel İşletmelerinde Bir Araştırma. Anatolia: Turizm Araştırmaları Dergisi, Cilt 25, Sayı 1, Bahar: 26 - 34, 2014. ISSN: 1300-4220 (1990-2014).

Kozak, M. (2018). Bilimsel araştırma: tasarım, yazım ve yayım teknikleri, 4. Baskı, Detay Yayıncılık. Ankara.

Landers, R. N.,andLoundsbury, J. W. (2006). An Investigation of big five and narrow personality traits in relation to internet usage. Computers in Human Behavior(22),283- 293

Laudon, K.C.,andLaudon, J.P. (2002). Management information systems: Managing the digital firm (7th ed.). Upper SaddleRiver, NJ: Prentice Hall.

Li, S., ve Chung, T. , 2006, Internet function and internet addictive behaviour, Computers in Human Behaviour, 22,1067-1071.

Lim, V. K. G., (2002), The it way of loafing on the job: cyberloafing, neutralizing and organizational justice, Journal of Organizational Behavior, 23(5),675- 694.

Lim, V. K. G.,andTeo, T. S. H. (2005). Prevalence, perceived seriousness, justification and regulation of cyberloafing in Singapore. Information \& Management, 42(8), 1081-1093.

Lim, V. K.,andChen, D. J. (2012). Cyberloafing at the workplace: gain or drain on work? Behaviour \& Information Technology, 31(4), 343-353.

Mercado, B. K.,Giordano, C., and Dilchert, S. (2017). A meta-analytic investigation of cyberloafing. CareerDevelopment International, 22(5), 546-564.

Örücü, Edip ve Yıldız, Harun (2014). “İşyerinde kişisel internet ve teknoloji kullanımı: sanal kaytarma”, Ege Akademik Bakı̧ Dergisi, 14(1), 99-114

Örücü, E. ve Özüdoğru, M. (2019). Örgütsel güven ile sanal kaytarma davranışları arasındaki ilişkinin belirlenmesine yönelik bir çalışma. Adnan Menderes Üniversitesi, Sosyal Bilimler Enstitüsü Dergisi, Cilt: 5(3), 66-80.

Ramayah, T., (2010), Personal web usage and work in efficiency. Business Strategy Series, 11 (5), $295-301$.

Pindek, S., Krajcevska and Spector, E. P. (2018). Cyberloafing as a coping mechanism: dealing with workplace boredom. Computers in Human Behavior, 86, 147-152.

Seçilmiş, C. ve Yılmaz, B., (2018). An investigatıon of the relationship between travel agencyes employee's cyberloafing behaviors and work motivation, Tourism, Leisure and Global Change, (5),372-377. 
Seymour, L. and Nadasen, K. (2007). Web Access for it staff: a developing world perspective on web abuse, The Electronic Library, 25 (5),543-557

Serttaş, O. ve Şimşek, G . (2017). Konaklama işletmelerinde siber aylaklık: çalışanların demografik özellikleri ile siber aylaklıkları üzerine bir araştırma. Uluslararası İktisadi ve İdari Bilimler Dergisi, 3 (1) , 20-34 .

Syrek, C. J., Kühnel, J., Vahle-Hinz, T., and De Bloom, J. (2018). Share, like, twitter, and connect: Ecological momentary assessment to examine the relationship betweenn on work social media use at work and work engagement. Work \& Stress, 32(3), 209-227

Turunç, Ö. (2015). İş stresi- kaytarma ilişkisinde liderin rolü: turizm sektöründe bir araştırma. Uluslararası İktisadi ve İdari Bilimler Dergisi, 1 (2), 142-159.

Ugrin, J. C. and Pearson, J. M. (2013). The effects of sanctions and stigmas on cyberloafing. Computers in Human Behavior, 29(3), 812-820.

Ulukapı, H.- Ç. ve Yılmaz, A. (2014), “Algılanan işe adanmışlığın sanal kaytarma davranışı üzerindeki etkisinin incelenmesi: Selçuk üniversitesi örneği”, 2. Örgütsel Davranış Kongresi, Kayseri, 7-8 Kasım, (65-72).

Van Doorn, O. N., (2011), Cyberloafing: a multi-dimensional construct placed in a theoretical framework. Yüksek Lisans Tezi. Eindhoven University of Technology, Department Industrial Engineering and Innovation Sciences.

Van Hooff, M. L. M. and Van Hooft, E. A. J. (2014). Boredom at work: proximal and distal consequences of affective work-related boredom. Journal of Occupational Health Psychology, 19(3), 348-359.

Vitak, J.,Crouse, J. andLarose, R. (2011), Personal internet use at work: understanding cybers lacking, Computers in Human Behavior, 27(5), 1751-1759

Yıldırım, F. (2018). Otel işletmelerinde yıldırma ve işe yabancılaşmanın sanal kaytarma davranışına etkisinde psikolojik sözleşme ihlali algısının aracıllk rolü, Journal of Tourism and Gastronomy Studies, 6(4), 21-39.

Zacher, H.,Brailsford, H. A. and Parker, S. L. (2014). Micro-breaks matter: A diary study on the effects of energy management strategies on occupational well-being. Journal of Vocational Behavior, 85(3), 287-297.

Zimmerman, E. (2002). HR must know when employee surveillance crosses thel ine. Work force, 81 (2), 38-45. 